\title{
Etnia e gênero como variáveis sombra na saúde mental
}

Ethnicity and gender as variable shadow on mental health

Lucia Cristina dos Santos Rosa', Rosana Teresa Onocko Campos²

'Pós-Doutoranda em Saúde Coletiva pela Universidade Estadual de Campinas (UNICAMP) - Campinas (SP), Brasil.

Professora do Departamento de Serviço

Social da Universidade Federal do Piauí (UFPI)

- Teresina (PI), Brasil.

luciacsrosa@yahoo.com.br

2 Doutora em Saúde Coletiva pela Universidade Estadual de Campinas

(UNICAMP) - Campinas (SP), Brasil..Professora do Departamento de Saúde Coletiva da Universidade Estadual de Campinas (UNICAMP) - Campinas (SP), Brasil.

rosanaoc@mpc.com.br
RESUMO O objetivo deste estudo é efetivar uma revisão de literatura a partir dos pertencimentos identitários, sobretudo das características relacionadas a etnia e gênero e suas intersecções com a saúde mental. Fundamenta-se na concepção de identidade de Antonio Carlos Ciampa e nas variáveis sombra enfatizadas por Benedeto Saraceno. Promovese um balanço do estado da arte a partir de levantamento no SciELO, Medline e LILACS. Conclui-se que a maioria dos estudos volta-se para temáticas relacionadas à mulher. A violência contra a mulher ganha proeminência nas suas repercussões negativas sobre a saúde emocional, sendo destacada a sua condição de vítima.

PALAVRAS CHAVE: Gênero; Etnia; Cidadania; Saúde mental.

ABSTRACT The goal of this study is to carry out a literature review based on identity belongings, especially characteristics related to ethnicity and gender as well as its intersections in mental health. It is based on the concept of identity by Antonio Carlos Ciampa and variable shadow emphasized by Benedeto Saraceno. It promotes a balance of state of the art from the survey conducted by Scielo, Medline and Lilacs. It is concluded that the majority of studies turns to themes related to a woman. It is concluded that the majority of studies turns to themes related to the female. Violence against women gained prominence in their negative impact on emotional health, highlighting her victim condition.

KEYWORDS: Gender; Ethnicity; Citizenship; Mental health. 


\section{Introdução}

Com a reforma psiquiátrica brasileira, a assunção da pessoa com transtorno mental à condição de cidadã implicou simultaneamente metamorfoses em sua identidade, adquirindo um novo status social em uma circunstância da intensa mudança social.

Nesse, contexto o desafio é pluralizar sua identidade, conformada no modelo manicomial como uma identidade estigmatizada, pois é atravessada pelas insígnias da incapacidade e da periculosidade.

As identidades são socialmente construídas nas interaçôes cotidianas entre o sujeito e seu contexto social. Desse modo, o sujeito é produtor de sua identidade, ao mesmo tempo que esta é produto das condições sócio-históricas. $\mathrm{O}$ sujeito encarna, assim, relaçóes sociais. Mas também pode influir para as alteraçôes ou permanências no seu contexto social, sob determinadas circunstâncias.

À medida que a sociedade muda, o sujeito também é exigido a mudar, situando-se em um processo de constante transformação e incorporação de novas identidades. Contudo, mantém uma unidade que conforma uma totalidade dentro de si, na dialética entre mudança e permanência.

Segundo Ciampa (1998), a identidade é processual, 'metamorfose', representando a pessoa e a engendrando. Sujeito e sociedade se constituem mutuamente, um influindo sobre o outro, em uma dinâmica que impõe a condição de sujeito ativo, construtivo, em permanente interação.

Com os ganhos na condição de sujeito de direito da pessoa com transtorno mental, supóe-se que houve uma melhor visualização de outros pertencimentos identitários, que permitiram alteraçóes substantivas na identidade pautada pelo estigma para outra em que dimensóes étnicas e de gênero passaram a mediar suas relaçóes com a sociedade.

Nesse contexto, vários elementos assumem papel de destaque na avaliação da evolução de um transtorno mental, assim como na estratégia da intervenção em saúde mental. Saraceno (1994) classifica esses elementos dividindo-os em variáveis fortes e variáveis sombra. As primeiras são delimitadas por: "diagnóstico; idade; agudeza ou cronicidade do quadro; e historia da enfermidade" (p.21). As variáveis denominadas como 'sombra' contornam uma gama de fatores que se relacionam com: a) os recursos individuais da pessoa com transtorno mental ('o nível de capacidade intelectual e o grau de informaçáo' da pessoa com transtorno mental, seu status social, sua condição de solidáo ou não e o sexo. (p.21).

Conforme alerta Saraceno (1994):

Essas variáveis geralmente são deixadas à sombra porque são consideradas 'irrelevantes' no que diz respeito à evolução da enfermidade $e$ à estratégia de intervenção. Entretanto, é provável que um paciente 'piore muito mais pela falta de todos (ou alguns) desses recursos do que pelo tipo de enfermidade (Diagnóstico). Na realidade, pacientes que têm um mesmo diagnóstico desenvolvem diferentes evoluçóes e resultados, assim como pacientes que têm uma mesma terapia farmacológica desenvolvem diferentes evoluçóes e resultados. Por isso, o diagnóstico sozinho, assim como o fato de que o paciente tome alguns psicofármacos, náo orienta para um prognóstico. O diagnóstico pode 'ajudar' a estabelecer a oportunidade de uma terapia farmacológica, porém 'não a estabelecer estratégias' de intervençâo mais complexas e articuladas (...) O que determina resultados tão diferentes é: boa ou má utilização das medidas terapêuticas; a existência elou influência das variáveis sombra'. (p. 22, grifos do autor).

Desse modo, a pessoa com transtorno mental é restituída em sua integralidade e o foco da atenção dos profissionais de saúde mental se amplia para além dos sintomas e dos medicamentos, para outras dimensóes sociais da vida, que engloba sua existência sofrimento (ROTELLI, 1990). Assim, os determinantes sociais do processo saúde-doença ganham ênfase e o social passa a ser uma dimensão que requer ser evidenciada na intervenção dos profissionais de saúde mental. Reconstituem-se os múltiplos pertencimentos que contornam a identidade da pessoa com transtorno mental, 
destacando-se, no escopo deste estudo, o gênero acrescido com as dimensóes étnico-raciais, que se constituíram, associados aos condicionantes de classe social, as bases fundantes das desigualdades que historicamente marcaram a dinâmica da sociedade brasileira.

\section{Metodologia}

O presente estudo baseou-se no levantamento do 'estado da arte' ou 'estado do conhecimento', como define Ferreira (2002), isto é, "mapeou e discutiu a produção acadêmica (...) na perspectiva de informar os aspectos e dimensôes" mais privilegiados e destacados remetidos às dimensóes de gênero e etnia na interface com a saúde mental, contextualizando o que se materializou até o ano 2011. Privilegiou-se a produção científica (artigos, teses e outros) disponibilizada em português, eletronicamente, na Bireme (Biblioteca Virtual em Saúde), a qual abrange como base de dados a LILACS, o Medline e o SciELO (acessado em 28 de junho de 2012), empregando-se por descritores os termos etnia, saúde mental, mulher, homem e gênero. Enfocando as categorias étnico-racial e saúde mental, nenhum artigo em português foi localizado. O emprego dos descritores saúde mental, mulher, gênero resultou em 29 textos, descartando-se 9 em função de: 7 textos completos não estarem disponíveis; um por ser uma repetição de outro existente, e um outro em função de o conteúdo não fazer conexão com as categorias em tela.

O tipo de produção predominante foi constituída de artigos, em número de 12; 7 teses; e 1 dossiê.

A análise de conteúdo, na sua vertente temática, foi empregada para tratamento do material acessado.

Discutir os pertencimentos identitários de gênero e etnia pode permitir ampliar a análise dos indicadores de avaliação na democratização de acesso e permanência nos serviços de saúde, a partir de tais categorias. Ainda permite avaliar a distribuição dos transtornos mentais e de seus agravos conforme o gênero e a etnicidade. Possibilita também apreender outras identidades igualmente tendentes à estigmatização social que, somadas ao transtorno mental, podem agravar a condição social da pessoa com transtorno mental ou potencializar outras articulaçóes que permitam produzir mais vida, recriando e investindo em outras identidades. As categorias em apreço exigem interlocuçóes seminais com outros campos de saber, constituindo, assim, uma exigência interdisciplinar.

\section{Resultados e discussão}

Rabelo e Tavares (2008), em análise da literatura que processam sobre as interfaces entre saúde mental e gênero, informam que duas tendências predominam teoricamente. Uma voltada para a epidemiologia, comparando a distribuiçâo desigual dos transtornos mentais entre homens e mulheres. As mulheres seriam mais vulneráveis aos transtornos mentais leves, sobretudo à depressão. De outro lado, os estudos de natureza sociológica, colocando em enlevo a violência, evidenciam como os atravessamentos de gênero influenciam o processo saúde-doença.

Com o mapeamento realizado, o resultado confirmou tais inclinaçóes entre os estudos, acrescentando-se novos itens e olhares. Identificaram-se duas vertentes envolvendo as dimensóes de gênero. De um lado, os estudos dirigidos para a questão de gênero com primazia sobre o polo considerado historicamente dominado da relação, ou seja, as mulheres, com 15 textos. Destes, 9 tratam diretamente da violência contra a mulher, preponderando a violência entre parceiro íntimo/conjugal (em 8 deles).

De um modo geral, é possível afirmar que nesses estudos a categoria gênero ressaltou a vulnerabilidade $\mathrm{da}$ mulher em um contexto relacional envolvendo as hierarquias sociais/relaçóes de poder.

Uma segunda perspectiva explora outras orientaçôes sexuais, sobretudo a transexualidade e as mulheres lésbicas, despatologizando olhares e resignificando a vivência deste segmento.

Apenas um texto, de autoria de Grubits e Darrault-Harris (2003), traz à baila questóes étnico-raciais, a partir da população indígena.

A violência contra a mulher ganha realce, pois, historicamente, na sociedade moderna capitalista, a partir da institucionalização da divisão sexual do trabalho que 
reforçou relações assimétricas, inclusive reforçadas por todo aparato jurídico estatal, a mulher ocupou um lugar subordinado, sendo frequentemente vítima da violência em suas várias dimensóes e contextos. Primeiramente, por náo ser considerada cidadã, o que passa a ocorrer no contexto brasileiro a partir dos anos 1930 , com o direito ao voto.

Com o revigoramento da sociedade civil, na década de 1970, emergem o movimento de mulheres e o movimento feminista, que passam a dar visibilidade a várias demandas para alterar a condição feminina na sociedade brasileira, lutando contra sua opressão (PINTO, 2003) e por igualdade de direitos de homens e mulheres.

Há várias conquistas em termos de políticas públicas, uma delas materializada na institucionalização, em 2004, do Programa de Atenção Integral à Saúde da Mulher (PAISM). Mas os avanços ocorrem de maneira contraditória, com a persistência da violência contra um número significativo de mulheres $\mathrm{e}$ da pouca ampliação da participação dos homens em arenas que permanecem com nichos femininos, como o trabalho doméstico não remunerado.

Desde 1991, a Organização Pan-Americana da Saúde reconhece a violência como causa do adoecimento das mulheres. Para a ONU, violência de gênero é

\section{[...] qualquer ato de violência baseada no gê- nero que resulte ou possa resultar em dano ou sofrimento fisico, sexual ou psicológico a uma mulher, incluindo ameaça de tais atos, coerçâo, privação arbitrária da liberdade, seja no âmbi- to publico ou privado. (UNITED NATIONS GENERAL ASSEMBLY, 1993).}

Ela pode vitimizar homens, mas seu alvo principal são as mulheres, sendo seu perpetrador um homem, comumente do círculo próximo.

A violência muito frequentemente causa prejuízos psicossociais à mulher, tais como isolamento social, maior dependência econômica, entre outros.

Há vários instrumentos para mensurar a violência contra a mulher, o que permite padronizar as formas de coleta de dados, bem como possibilita replicar estudos ou compará-los, inclusive, transculturalmente.

Para tanto, há necessidade de validá-los, o que é tratado no artigo de autoria de Schraiber et al. (2010) com relação ao WHO VAW, para estimar a violência de gênero contra a mulher, tendo por base empírica São Paulo e a Zona da Mata de Pernambuco. Os autores concluem que tal instrumento é adequado para estimar a violência, para qual foi produzido, apresentando alta consistência interna, e discrimina os diferentes tipos de violência: psicológica, física e sexual, os quais, tanto no contexto brasileiro quanto no internacional, se superpóem.

Muñoz (2010), buscando entender a violência contra a mulher no Brasil do início do século XX, investe no caso Elza, uma alemã de classe média alta que o marido, em conluio com todo aparato médico e policial, interna por não aceitar o seu pedido de divórcio, recebendo diagnóstico de 'degeneração atípica'. Torna-se um caso emblemático por colocar em xeque a ordem patriarcal.

Esse é um caso paradigmático que se sintoniza com o consenso dos estudiosos de que a violência remete à saúde psíquica da mulher. Tal fato se espelha também nos diferenciais de prevalência dos transtornos mentais em mulheres, como constata Arôca (2009), destacando que entre elas predominam os transtornos mentais comuns que, nas camadas populares, são associados ao 'sofrimento dos nervos'.

Os danos impostos à mulher podem repercutir igualmente na vida dos filhos, sendo, portanto, um dos determinantes no processo saúde-doença para algumas famílias.

Oliveira (2008) informa que "[...] as mulheres com história de violência apresentaram uma densidade de incidência de desmame 35\% maior do que as não expostas" (p. 10), concluindo que a violência física grave na gestação constitui "[...] um fator de risco para a interrupção precoce" (p. 72) do aleitamento materno exclusivo.

Durand et al. (2011), ao explorar a repercussão da exposição à violência por parceiro íntimo no comportamento do filho, conclui que a 
VPI mostrou-se fortemente associada aos problemas de comportamento dos filhos e a força dessa associação foi crescente, conforme a gravidade da violência e o número de problemas considerados. (p.359).

Diante do quadro de vulnerabilidade da mulher, das dificuldades dos serviços de saúde e do sentimento de impotência dos profissionais em oferecer uma assistência resolutiva, algumas pesquisas focalizam a formação de pessoas para esse tipo de intervenção.

Pedrosa e Spink (2011) mostram o quão distante das grades curriculares e da formação médica esse recorte se encontra, o que promove uma dissociação entre as queixas das mulheres com relação às suas vivências da violência. Segundo as autoras, os registros em prontuários se resumem aos sintomas e prescrições biomédicas, ignorando o contexto de vida destas mulheres que tendem a sofrer com a violência institucional perpetrada por práticas profissionais que, atravessadas por diferenças de classe social, desconsideram a pobreza e as múltiplas exclusóes a que são submetidas, desconsiderando suas repercussóes no processo saúde-doença-cuidado.

Por sua vez, Angulo-Tuesta (1997) analisa as representaçóes sociais dos profissionais de dois serviços de atenção primária (Centros de Saúde e Programa Médico de Família), bem como o papel que os mesmos desempenham diante desse tipo de violência. As diferenças constatadas na assistência prestada entre os serviços são imputadas aos diferentes modelos organizativos, favorecedores ou não da atenção integral à mulher em situação de violência de gênero.

Os profissionais admitem que nos atendimentos, no geral, as mulheres silenciam sobre a violência de gênero, mas, contraditoriamente, intensificam a procura por serviços de saúde, sendo estereotipadas como 'poliqueixosas'. No Programa Médico de Família, pelo fato de a própria organizaçáo do processo de trabalho acontecer na comunidade, com acompanhamento longitudinal, os profissionais têm maior facilidade em confirmar suspeita de violência contra a mulher. E compreendem a violência como um "problema complexo e delicado" (p.130), apresentando dificuldades em sua abordagem e manejo.
Madge Porto (2006), ao avaliar o que pensam os gestores municipais do SUS sobre o atendimento psicológico envolvendo a violência contra a mulher, constata que aqueles dissociam tal procedimento da Política municipal de saúde mental, havendo uma tendência de psicologização da questão, reduzida ao atendimento psicológico. $\mathrm{Na}$ análise da autora, o atendimento psicológico figura como uma intervenção isolada, desvinculada de questôes de saúde mais amplas, como a saúde mental ou mesmo a saúde da mulher.

Vislumbrando a necessidade de ampliaçấo do foco da atenção, Ballarin et al. (2008) constatam as dificuldades da atenção integral à saúde da mulher com transtorno mental, que requer açóes intersetoriais dada a associação da enfermidade com a pobreza, com as sobrecargas em múltiplas arenas, a violência, a discriminação, entre outros. Os autores mostram as dificuldades das mesmas em conseguir exames ginecológicos com regularidade, sendo, em muitas circunstâncias, expostas à gravidez indesejada; ao câncer de mama e à perda do 'poder familiar' sobre os filhos pela precária atuação promotora da integralidade.

Alguns estudos, na perspectiva de superar a visão de impotência dos profissionais e a meramente vitimizatória das mulheres, apostando na promoçáo de qualidade de vida, fortalecendo o protagonismo e o empoderamento, investem em açóes assistenciais inovadoras, recortadas pela categoria gênero.

Faúndes et al. (2006) propóem procedimentos e formas de atuação profissional para vitimas de estupro para além das açóes pontuais de emergência e dos protocolos. Incorporam açóes de seguimento e orientação para os diferentes públicos. Tal proposta emerge da identificação da falta de preparo de ginecologistas e obstetras para atuarem nesse cenário. Insistem na importância da atenção psicológica e de pessoal.

Neves e Cabral (2008), ao analisarem a centralidade da mãe no cuidado de crianças com necessidades especiais em saúde, identificam o peso das sobrecargas que a oprimem, expresso em isolamento social, desgaste físico e mental. No afẫ de se empoderar individualmente, essas mulheres se apoiam na expectativa social de que se construam como 'boas mães', abnegadas e com dedicação incondicional aos filhos. 
Como constatam as autoras, tal estratégia é reforçada pelos profissionais dos serviços de saúde ao limitar o papel social das mulheres à 'mãezinhas', reduzindo sua identidade à maternidade. Suprimem, assim, sua condição feminina.

As autoras observam que a troca de experiências entre mulheres que vivenciam situação limite configura fonte coletiva de empoderamento, propiciando repensar a produção de um tempo para si, o que, por sua vez, a revigora na própria tarefa de cuidar.

Rabelo e Tavares (2008), explorando uma experiência entre CAPS e ESF, mostram a associação entre sofrimento e relaçóes sócio-afetivas com o objetivo de questionar o uso de ansiolíticos entre as mulheres. Ao buscar redirecionar o encaminhamento da abordagem das mulheres, capacitando equipes, reencaminham a abordagem para o que está subjacente ao uso ou à demanda por ansiolíticos. Ou seja, a subordinação das mulheres aos maridos, considerados "homens carrapatos", ou seja, "um homem que a massacra e que a impede de viver a própria vida, um homem cuja ação se limita a sugar o sangue da mulher" (p. 140). Como resposta de saída individual, recorre a serviços de saúde visando a aplacar seu sofrimento, tendo por retorno a medicalização. Com essa experiência, desenha-se a possibilidade de redirecionar a intervenção.

No mesmo diapasão se situa a tese de Barbosa (2008), que analisa o trabalho com um grupo terapêutico voltado para mulheres alcoolistas, sob o foco da redução de danos. A grupalização promove uma melhora na imagem de si e fomenta novas práticas em saúde. Como espaço, inclusive, lúcido e intermediado por ações de geração de renda, tais como a oficina de bijuteria, alimentação viva, produção e exibição de vídeos e atividades de expressão como o canto, a dança e o teatro, o cuidado é diferenciado segundo a ótica de gênero. As mulheres aprendem novas habilidades, inclusive relacionais, a 'saber fazer'; se identificam com a problemática das outras, o que permite um repensar sobre a vida e as estratégias de enfrentamento de problemas ou de certas dificuldades pessoais, como a timidez. Além de fomentar a interação com um público fora do espaço clínico, através da exposição e da comercialização de produtos, a experiência forja uma nova abordagem do alcoolismo e do cuidado em saúde. Há modificação da autoimagem social da mulher alcoolista pelo "apresentar, ensinar e trabalhar", e pela nova compreensão de que "são capazes, mesmo sendo alcoólatras" (p.110).

Panoramicamente, observa-se a emergência de alteraçóes substanciais na produção acadêmica, que passa de uma abordagem preponderantemente vitimizatória das mulheres para outra em que novos desenhos assistenciais são traçados, bem como a produção de coletivos de pessoas que vivenciam situação em comum se constrói, ampliando o fortalecimento da cidadania, o protagonismo.

O acumulo teórico permitiu um bom diagnóstico da situação da saúde na mulher na sociedade, principalmente a partir do processo de redemocratização da sociedade brasileira. Com a democracia consolidada e o Estado ampliado, incorporando a sociedade civil, a necessidade de intervençóes mais propositivas parece se evidenciar, alargando as possibilidades de construção de novos processos de trabalho em saúde.

Observa-se, ainda, nos textos analisados o predomínio de uma tendência de leitura focada nas mulheres de maneira una e homogeneizadora, sem destacar, por exemplo, outros pertencimentos, tais como étnico-raciais, etários/intergeracionais ou mesmo de classe social. Aliás, questôes étnicas aparecem em apenas um texto, com relação à população indígena, e sem conexão direta com a saúde mental.

Nesse contexto, destaca-se a importância de evitar leituras homogeneizantes da vivência, quer masculina ou feminina, haja vista que o próprio movimento feminista reconhece a pluralidade da vivência e das identidades das (e entre) mulheres.

Em suma, o que está posto como desafio é a desconstrução da medicalização da mulher, o que demanda outra organização dos serviços de saúde e o fortalecimento de seu protagonismo social para além de experiências pontuais e episódicas e da saúde.

Outro grupo de estudos se dedica às mulheres sob outros prismas, promovendo estudos comparativos com a realidade masculina em vários cenários.

É consensual na literatura o reconhecimento das diferenças na prevalência de transtornos mentais entre homens e mulheres. Andrade, Viana e Silveira (2006), 
ao promoverem uma revisão de literatura, constatam que há diferenças de gênero na incidência, na prevalência e no curso dos transtornos mentais. As mulheres estariam mais propensas - 1,5 a mais - que os homens durante a vida a ter um transtorno mental. São mais suscetíveis a apresentar sintomas ansiosos, depressivos, transtornos alimentares e a serem vítimas de situação de violência de gênero, que, no geral, deixam como uma das sequelas a depressão e o transtorno de estresse póstraumático. Ansiedade e alteraçóes de humor podem se intensificar ou apresentar comorbidade em períodos em que intensas alterações hormonais são esperadas, tais como: pré-menstruais, puerpério e menopausa. Por sua vez, os homens apresentam maior prevalência de transtornos relacionados ao uso indevido de substâncias psicoativas,

transtornos de personalidade anti-social e esquizotípica, transtornos do controle de impulsos e de déficit de atenção e hiperatividade na infância e na idade adulta. (p. 44).

apresentando também maiores taxas de suicídio. Tais diferenciais são atribuídos às particularidades biológicas; a questóes psicossociais; às diferentes pressóes sociais; às diferentes formas de enfrentar os problemas e de buscar soluçóes; e à maior facilidade da mulher em detectar alteraçóes na própria saúde e em procurar ajuda nos serviços de saúde.

Marín-León et al. (2007), ao ter como principal ferramenta uma lista com 17 problemas da comunidade, a partir de variáveis sóciodemográficas, mostra a diferença de intensidade na leitura dos mesmos, apresentada por homens e mulheres, concluindo que a "proporção de mulheres que caracterizaram os problemas da lista como graves foi sempre maior que a dos homens" (p. 1091). Os autores interpretam tal divergência afirmando que as mulheres são mais influenciadas emocionalmente pelos problemas e falam mais sobre eles.

Grubits e Darrault-Harris (2003), ao compararem duas comunidades indígenas e as manifestaçóes de gênero a partir do desenho de crianças, identificam as diferenças de comportamento e leitura de mundo entre meninas e meninos: as primeiras mais associadas ao espaço afetivo-familiar, enquanto os segundos buscariam expandir sua relação com o espaço público para a cidade.

Alguns estudos concentraram a atenção nas condições de trabalho a partir da categoria gênero.

Rocha e Debert-Ribeiro (2001), ao efetivarem um estudo comparativo entre homens e mulheres na profissão de analistas de sistemas, com base na ergonomia, observam alguns fatores em comum, produtores de prejuízos à saúde física e mental. Destacaram: sobrecarga de trabalho, pela demanda de realização em curto espaço temporal; "alto grau de responsabilidade; exigência mental do trabalho; e complexidade da tarefa" (p. 539). Distúrbios psicológicos foram igualmente detectados em homens e mulheres. Todavia, as mulheres ganharam proeminência na insatisfação com o trabalho, em sintomas visuais e osteomusculares e na maior "prevalência da fadiga e dos sintomas de depressão, irritabilidade e ansiedade" (p. 546). As diferenças negativas com relação às mulheres foram atribuídas às diferenças de percepção subjetiva e à superposição de responsabilidades e tarefas envolvendo dois universos distintos, o do mercado formal de trabalho, remunerado, e o mundo privado do trabalho doméstico, condensados na dupla jornada de trabalho. Tal fator é gerador de sobrecarga, o que repercute na saúde física e mental das mulheres.

Reafirmando tal entendimento, Vellozo (2010), ao analisar como as condiçóes de trabalho impactam na saúde de mulheres que trabalham como motoristas de ônibus urbanos, também evidencia o fenômeno da dupla jornada de trabalho, haja vista que o tempo de folga, que seria dedicado ao descanso e ao lazer, é vivenciado de maneira distinta em função do gênero. Os homens são dispensados cultural e socialmente desse encargo. Em função da mesma sobrecarga, as mulheres alegam que não dispóem de tempo para exercícios físicos regulares, o que poderia melhorar as repercussóes negativas das condições de trabalho, haja vista que a principal ferramenta desse tipo de trabalho - o ônibus - foi projetada ergonometricamente para os homens.

Condiçóes de trabalho igualmente desfavoráveis para ambos os sexos, segundo a autora, "repercutem de modo distinto na saúde dessas pessoas' devido às atribuiçóes de gênero" (p. 64). 
Este segundo aglomerado de estudos sobre a mulher confirma a visão anterior, vitimizatória. Mas, para além disso, mostra diferenças substanciais em termos epidemiológicos, sinalizando para sua maior vulnerabilidade a agravos, o que exige um outro olhar e uma outra conduta para esse segmento. Indica, ainda, as diferenças substanciais na leitura de mundo e de seus problemas entre pessoas do sexo masculino e do sexo feminino, bem como o avanço das mulheres em profissóes até então consideradas nichos masculinos, o que não deixa de impactar sua saúde. Na relação saúde-trabalhogênero, a dupla jornada de trabalho destacou-se como persistente e prejudicial à saúde da mulher.

Por fim, observa-se a ampliação das discussóes de gênero na produção acadêmica para além da vivência binária, incorporando de maneira positiva outras orientaçóes sexuais na perspectiva de resignificar olhares.

Dois artigos priorizando outras orientaçóes sexuais têm seu pioneirismo registrado através da temática direcionada para a despatologização da homossexualidade e da transexualidade (AMARAL, 2011). Outro volta-se para as demandas da área da saúde pelo segmento de lésbicas (REDE NACIONAL FEMINISTA DA SAÚDE, 2006), remetendo, inclusive, ao sofrimento implicado no preconceito e na discriminação socialmente imputados a esses grupos minoritários.

Em sua tese, Amaral (2011) reconstitui toda trajetória dos avanços tecnológicos/ científicos, a partir dos anos de 1950, que alteraram todo paradigma em torno do transexualismo, diferenciado desde entáo da homossexualidade e da travestilidade.

O transexualismo é concebido como

uma variação do gênero, cuja característica principal seria o desejo de modificação do sexo, [...] descrita como uma discordância entre o sexo fisico e a identidade de gênero, na qual seria necessário reestabelecer este alinhamento. (p.25).

A autora reconstitui a emergência de uma nova compreensão endocrinológica que indica que "todos os organismos são, em termos químicos, potencialmente de ambos os sexos" (p. 21), o que permitiu uma releitura em que masculino e feminino seriam pólos extremos de um eixo contínuo do sexo, a existência de situaçóes intermediárias, como individuos com anatomia masculina e caracteristicas fisicas el ou psicológicas femininas ou vice-versa, se tornou concebivel. (p. 21).

Tais mudanças permitem a modificação do sexo pela via dos hormônios e das cirurgias plásticas (cirurgias de redesignação), o que tem sido assegurado pelo SUS. Desloca-se, assim, o eixo analítico do sexo biológico para o sexo psicológico, metamorfoseado à identidade de gênero.

Nesse contexto, as demandas feministas se alteram, exigindo a "dissociação entre o exercício da sexualidade e a reprodução" (REDE NACIONAL FEMINISTA DA SAÚDE, 2006).

$\mathrm{O}$ 'sexual' é visto para além da violência. É associado também ao bem-estar das pessoas, no cerne da 'saúde sexual', na compreensão de que a sexualidade é um direito.

O movimento social do segmento lésbicas, gays, bissexuais, travestis, transexuais e transgêneros (LGBT), até então centrado nos programas de AIDS/HIV, se expande para outras arenas, pleiteando do SUS/Reforma Psiquiátrica a incorporação do uso do nome social nos formulários e no cotidiano de atendimento dos serviços de saúde, e investimento em pesquisa e assistência em saúde mental do grupo, particularmente remetendo ao uso indevido de substâncias psicoativas e ao suicídio. Açôes de combate à violência implicada com a homofobia são requeridas, sobretudo, no ambiente familiar e de trabalho.

A partir do levantamento bibliográfico efetivado conclui-se que, apesar da ampliação da categoria gênero para outros segmentos sociais, observou-se que houve pouca diversificação da identidade das pessoas com transtorno mental, ganhando destaque a mulher em uma perspectiva predominantemente vitimizatória. Dimensóes étnicas são raramente exploradas. Outras dimensóes da identidade de gênero, tais como outras orientaçôes sexuais, começam a ganhar visibilidade bem como o protagonismo de coletivos sociais, inclusive de mulheres, o que aponta para a necessidade de mudanças na organização dos serviços e na relaçáo dos mesmos com a sociedade em geral. 


\section{Referências}

AMARAL, D. M. Os desafios da despatologização da transexualidade: reflexões sobre a assistência a transexuais no Brasil. 2011. 107f. Tese (Doutorado em Saúde Coletiva) -Universidade do Estado do Rio de Janeiro, Rio de Janeiro, 2011.

ANDRADE, L. H. S.B.; VIANA, M. C.; SILVEIRA, C. M. Epidemiologia dos transtornos psiquiátricos na mulher. Revista de Psiquiatria Clinica, São Paulo, v. 33, n.2, p. 43-54, 2006.

ANGULO-TUESTA, A. J. Gênero e violência no âmbito doméstico: a perspectiva dos profissionais de saúde. 1997. 138f. Dissertação (Mestrado em Saúde Pública) - Fundação Oswaldo Cruz, Rio de Janeiro, 1997.

ARÔCA, S. R. S. Qualidade de vida: comparação entre o impacto de ter transtorno mental comum e a representação do Sofrimento dos Nervos sem mulheres. 2009.119 f. Dissertação (Mestrado em Saúde Pública) - Fundação Oswaldo Cruz, Rio de Janeiro, 2009.

BALLARIN, M. L. G. S.; FERIGATO, S. H.; CARVALHO, F. B. Serviços de atenção à saúde mental: reflexões sobre os desafios da atenção integral à saúde da mulher. O mundo da saúde, São Paulo, v. 32, n.4, p. 511-518, 2008.

BARBOSA, L. C. O fundo do poço pode se transformar em fundo de posso: trabalho com grupo de mulheres alcoolistas sob a perspectiva de redução de danos. 2008.139 f. Dissertação (Mestrado em Saúde Pública) - Fundação Oswaldo Cruz, Rio de Janeiro, 2008.

CIAMPA, A. C. A estória de Severino e a história de Severina: um ensaio de psicologia social. São Paulo: Brasiliense, 1998.

DURAND, J. G.; SCHRAIBER, L. B. FRANÇA-JUNIOR, I. BARROS, C. Repercussão da exposição à violência por parceiro íntimo no comportamento dos filhos. Revista de Saúde Pública, São Paulo, v.45, n.2, p. 355-364, 2011.

FAÚNDES, A et al. Violência sexual: procedimentos indicados e seus resultados no atendimento de urgência de mulheres vitimas de estupro. Revista Brasileira de Ginecologia e Obstetrícia, Rio de Janeiro, v.28, n.2, p. 126-135, 2006.

FERREIRA, N. S. A. As pesquisas denominadas "Estado da Arte", Educação \& Sociedade, Campinas, v. 23, n. 79, ago. 2002.

GRUBITS, S.; DARRAULT-HARRIS, I. Ambiente, identidade e cultura: reflexões sobre comunidades Guarani/Kaiowá e Kadiwéu de Mato Grosso do Sul. Psicologia e Sociedade, Belo Horizonte, v.15, n.1, p. 182-200, jan./jul. 2003.

MARÍN-LEÓN, L. et al. Percepção dos problemas da comunidade: influência de fatores sócio-demográficos e de saúde mental. Cadernos de Saúde Pública, Rio de Janeiro, v.23, n.5, p. 1089-1097, maio 2007.
MUÑOZ, P. F. N. Degeneração atípica: uma incursão ao arquivo de Elza. 2010. 191f. Dissertação (Mestrado em História das Ciências) Fundação Oswaldo Cruz, Rio de Janeiro, 2010.

NEVES, E. T.; CABRAL, I. E. Empoderamento da mulher cuidadora de crianças com necessidades especiais de saúde. Texto \& Contexto Enfermagem, Florianópolis, v. 17, n.3, p. 552-560, jul./set. 2008.

OLIVEIRA, A. S. D. Violência entre parceiros íntimos durante a gestação: um fator de risco para o desmame precoce. 2008. $217 \mathrm{f}$. Tese (Doutorado em Saúde Coletiva) - Universidade do Estado do Rio de Janeiro, Rio de Janeiro, 2008.

PEDROSA, C. M.; SPINK, M. J. P. A violência contra mulher no cotidiano dos serviços de saúde: desafios para a formação médica. Saúde e Sociedade, São Paulo, v. 20, n. 1, p.124-135, 2011.

PINTO, C.R. J. Uma história do feminismo no Brasil. São Paulo: Fundação Perseu Abramo, 2003. 119 p.

PORTO, M. Violência contra a mulher e atendimento psicológico: o que pensam os/as gestores/as municipais do SUS. Psicologia, Ciência e profissão, Brasília, v.26, n.3, p. 426-439, 2006.

RABELO, I. V. M.; TAVARES, R. C. Homens carrapatos e suas mulheres: relato de experiência em saúde mental na Estratégia Saúde da Família. Saúde em Debate, Rio de Janeiro, v. 32, n. 78-80, p. 133-142, jan/dez 2008.

REDE NACIONAL FEMINISTA DE SAÚDE. Dossiê: saúde das mulheres lésbicas. Belo Horizonte: Rede Nacional Feminista de saúde, 2006. 41 p.

ROCHA, L. E.; DEBERT-RIBEIRO, M. Trabalho, saúde e gênero: estudo comparativo sobre analistas de sistemas. Revista de Saúde Pública, São Paulo, v. 35, n. 6, p. 539-547, 2001.

SARACENO, B. Manual de saúde mental. São Paulo: Hucitec, 1994.

SCHRAIBER, L. B. et al. Validade do instrumento WHO VAW STUDY para estimar violência de gênero contra a mulher. Revista de Saúde Pública, São Paulo, v. 44, n.4, p. 658-666, 2010.

UNITED NATIONS GENERAL ASSEMBLY. Declaration on the elimination of violence against women. Geneva, 1993. $7 f$.

VELLOZO, D. P. M. Mulheres ao volante...- uma análise de gênero, saúde e trabalho em mulheres motoristas de ônibus na cidade do Rio de Janeiro. 2010. 100f. Dissertação (Mestrado em Saúde Pública) - Fundação Oswaldo Cruz, Rio de Janeiro, 2010.

Recebido para publicação em Março/2012

Versão definitiva em Julho/2012

Suporte financeiro: não houve

Conflito de interesse: inexistente 